Review

\title{
A Review of Neoadjuvant Chemoradiotherapy for Locally Advanced Rectal Cancer
}

\author{
Yi Li², Ji Wang 3 , Xiaowei Ma4, Li Tan4, Yanli Yan ${ }^{4}$, Chaofan Xue ${ }^{4}$, Beina Hui ${ }^{1}$, Rui Liu ${ }^{1}$, Hailin Ma ${ }^{1}$ and Juan \\ $\operatorname{Ren}^{1,} \otimes$ \\ 1. Department of Radiotherapy, Oncology Department, First Affiliated Hospital of Xi'an Jiaotong University, Xi'an, Shaanxi 710061, P.R. China \\ 2. Department of Chemotherapy, Oncology Department, First Affiliated Hospital of Xi' an Jiaotong University, Xi'an, Shaanxi 710061, P.R. China, \\ 3. Intensive Care Unit, China Mei Tan General Hospital, ChaoYang, Beijing 100028, P.R. China, \\ 4. Medical School, Xi'an Jiaotong University, Xi'an, Shaanxi 710061, P.R. China. \\ $\triangle$ Corresponding author: Dr. Juan Ren, Department of Radiotherapy, Oncology Department, First Affiliated Hospital of Xi'an Jiaotong University, Xi'an, \\ Shaanxi, 710061, P.R. China. E-mail: 869491533@qq.com
}

(C) Ivyspring International Publisher. Reproduction is permitted for personal, noncommercial use, provided that the article is in whole, unmodified, and properly cited. See http://ivyspring.com/terms for terms and conditions.

Received: 2016.03.03; Accepted: 2016.06.04; Published: 2016.07.17

\begin{abstract}
Neoadjuvant chemoradiotherapy has become the standard treatment for locally advanced rectal cancer. Neoadjuvant chemoradiotherapy not only can reduce tumor size and recurrence, but also increase the tumor resection rate and anus retention rate with very slight side effect. Comparing with preoperative chemotherapy, preoperative chemoradiotherapy can further reduce the local recurrence rate and downstage. Middle and low rectal cancers can benefit more from neoadjuvant chemradiotherapy than high rectal cancer. It needs to refine the selection of appropriate patients and irradiation modes for neoadjuvant chemoradiotherapy. Different therapeutic reactions to neoadjuvant chemoradiotherapy affect the type of surgical techniques, hence calling for the need of much attention. Furthermore, many problems such as accurate staging before surgery, selection of suitable neoadjuvant chemoradiotherapy method, and sensitivity prediction to preoperative radiotherapy need to be well settled.
\end{abstract}

Key words: Rectal cancer, preoperative concurrent chemoradiotherapy

\section{Introduction}

Colorectal cancer is the fourth most common cancer worldwide, with rectal cancer estimated to be 39670. The etiology of colorectal cancer involves multiple genes and three possible pathways: chromosomal instability, mismatch repair (MMR) and the hypermethylation of the promoter of the MLH1 gene. Mutations in genes such as APC, k-ras, and p53 are associated with chromosomal instability. Microsatellite instability (MSI) is a genetic hypermutability which is present in about $90 \%$ of HNPCCs that carry germline inactivation in DNA mismatch repair genes (transform growth factor- $\beta$ receptor $\Pi$, the proapoptotic BAX gene and $\beta$-catenin). About $12-15 \%$ of sporadic cancer shows MSI.

Careful consideration of primary tumor, regional lymph node and distance metastasis will improve the survival of rectal cancer with the selection of appropriate treatment. Three major treatments including surgery, radiotherapy, and chemotherapy, must be well integrated. Combined treatment reduces loco-regional recurrences but the overall survival rate has not been remarkably improved. With better staging, better surgery technique, and incorporation of radiotherapy, slightly better 5-year survival rate has been reported in several large randomized trials $[1,2]$.

The most important prognostic factor for overall survival rate is the pathologic extent of disease (TNM stage), lymphatic invasion, vascular invasion, pathologic type, circumferential resection margin and the type of surgical technique (the length of the cutting edge and degree of lymph node dissection). Downstage effect of neoadjuvant radiochemotherapy 
(nCRT) is also considered as a risk factor.

The loco-regional recurrence rate of resectable stage II III rectal cancer patients was $15 \%$ to $65 \%$. Even with the total mesorectal excision (TME), local regional recurrence rate of stage III patients is up to about $20 \% \sim 30 \%$. To improve the local control rate and long-term survival rate, it is necessary for resectable stage II $\sim$ III patients to receive neoadjuvant therapy before surgery. Preoperative concurrent radiochemotherapy (nCRT) have become the standard treatment for resectable stage II $\sim$ III patients. For unresectable locally advanced rectal cancer, preoperative concurrent chemoradiotherapy is the only standard treatment, and most of these patients become resectable after the nCRT.

Preoperative chemoradiotherapy has been recommended as the standard treatment for locally advanced middle and low rectal cancer. Preoperative chemoradiotherapy can reduce the tumor mass, block the tumor invasion, increase the tumor resection rate, and anus retention rate, reduce iatrogenic dissemination during operation, and reduce the local recurrence rate. This article summarized the progress of the preoperative chemoradiotherapy for rectal cancer.

\section{Concurrent preoperative chemoradiotherapy}

National Comprehensive Cancer Network
(NCCN) guidelines recommend preoperative concurrent chemoradiotherapy as a priority standard treatment for II/III rectal cancer. Clinical Trials FFCD 92-03 and EORTC 22921 studied preoperative radiotherapy and concurrent preoperative chemoradiotherapy from 1993 to 2003. The results showed that for patients with resectable rectal cancer, concurrent preoperative chemoradiotherapy significantly further improved the pathologic complete response (pCR) and local control rate, it decreased the pathological staging compared with preoperative radiotherapy, but failed to improve the long-term survival and retention rate of anal sphincter. Besides this, a recent report from Hwang showed that pathologic stage can predict prognosis in patients who gets preoperative chemoradiotherapy [3]. Comprehensive treatment is the only way to ensure the treatment efficacy for resectable stage II-III rectal cancer [4-9] (Table 1).

Concurrent preoperative chemoradiotherapy followed with total mesorectal excision (TME) surgery plus systemic chemotherapy is the firstly recommended standard treatment method [10].

Phase III randomized study in Netherlands showed that tumor location was a prognostic factor for treatment efficacy. Middle and lower rectal cancer benefited more from neoadjuvant chemradiotherapy compared with high rectal cancer [4-9] (Table 1).

Table 1. Randomize studies of preoperative concurrent chemoradiotherapy for rectal cancer.

\begin{tabular}{|c|c|c|c|c|c|c|}
\hline $\begin{array}{l}\text { Studies } \\
\text { (time) }\end{array}$ & Eligible criteria & Groups (cases) & $\begin{array}{l}5 \text { year local } \\
\text { recurrence } \\
\text { rate }(\%)\end{array}$ & $\begin{array}{l}5 \text { year } \\
\text { disease-free } \\
\text { survival rate (\%) }\end{array}$ & $\begin{array}{l}5 \text { year } \\
\text { survival rate } \\
(\%)\end{array}$ & pCR (\%) \\
\hline \multirow{2}{*}{$\begin{array}{l}\text { Sweden Brandengen } \\
(2008) \text { [4] }\end{array}$} & \multirow[t]{2}{*}{$\begin{array}{l}\text { unresectable } \\
\text { locally advanced } \\
\text { rectal cancer }\end{array}$} & $\begin{array}{l}\text { preoperative concurrent } \\
\text { chemoradiotherapy }(n=98)\end{array}$ & & $\begin{array}{l}63 \\
(p=0.003)\end{array}$ & $\begin{array}{l}66 \\
(p=0.09)\end{array}$ & $\begin{array}{l}16 \\
(p=0.04)\end{array}$ \\
\hline & & preoperative radiotherapy alone $(n=109)$ & & 44 & 53 & 7 \\
\hline \multirow{2}{*}{$\begin{array}{l}\text { CAO/ARO-094(2004) } \\
{[5]}\end{array}$} & \multirow[b]{2}{*}{$\mathrm{T}_{3-4} / \mathrm{N}+$} & $\begin{array}{l}\text { preoperative concurrent } \\
\text { chemoradiotherapy }(n=399)\end{array}$ & $\begin{array}{l}6 \\
(p=0.006)\end{array}$ & $\begin{array}{l}68 \\
(p>0.05)\end{array}$ & $\begin{array}{l}76 \\
(p>0.05)\end{array}$ & \\
\hline & & $\begin{array}{l}\text { postoperative concurrent } \\
\text { chemoradiotherapy }(n=237)\end{array}$ & 13 & 65 & 74 & \\
\hline \multirow[b]{2}{*}{ NSABP-R03(2009) [6] } & \multirow[b]{2}{*}{$\mathrm{T}_{3-4} / \mathrm{N}+$} & $\begin{array}{l}\text { preoperative concurrent } \\
\text { chemoradiotherapy }(n=123)\end{array}$ & $\begin{array}{l}23.9 \\
(p=0.0115)\end{array}$ & $\begin{array}{l}64.7 \\
(p=0.065)\end{array}$ & $\begin{array}{l}74.5 \\
(p=0.01)\end{array}$ & \\
\hline & & $\begin{array}{l}\text { postoperative concurrent } \\
\text { chemoradiotherapy }(n=131)\end{array}$ & 27.5 & 53.4 & 65.6 & \\
\hline \multirow[t]{2}{*}{$\begin{array}{l}\text { Poland study (2004) } \\
\text { [7] }\end{array}$} & \multirow[t]{2}{*}{$\begin{array}{l}\text { stage II III } \\
\text { resectable rectal } \\
\text { cancer }\end{array}$} & $\begin{array}{l}\text { preoperative concurrent } \\
\text { chemoradiotherapy }(n=157)\end{array}$ & & $\begin{array}{l}68 \\
(p>0.05)\end{array}$ & $\begin{array}{l}76 \\
(p>0.05)\end{array}$ & $\begin{array}{l}15 \\
(p<0.001)\end{array}$ \\
\hline & & $\begin{array}{l}\text { Preoperative radiotherapy alone }(5 \mathrm{~Gy} \times 5 \mathrm{f}) \\
(\mathrm{n}=155)\end{array}$ & & 65 & 74 & 1 \\
\hline \multirow[t]{2}{*}{ FFCD9203(2006) [8] } & \multirow[t]{2}{*}{$\begin{array}{l}\text { stage II III } \\
\text { resectable rectal } \\
\text { cancer }\end{array}$} & $\begin{array}{l}\text { preoperative concurrent } \\
\text { chemoradiotherapy }(n=375)\end{array}$ & $\begin{array}{l}8.1 \\
(p=0.004)\end{array}$ & & $\begin{array}{l}67.4 \\
(p=0.684)\end{array}$ & $\begin{array}{l}11.4 \\
(p \\
=0.001)\end{array}$ \\
\hline & & Preoperative radiotherapy alone $(n=367)$ & 16.5 & & 66.9 & 3.6 \\
\hline \multirow[t]{2}{*}{$\begin{array}{l}\text { EORTC22921 (2006) } \\
{[9]}\end{array}$} & \multirow[t]{2}{*}{$\begin{array}{l}\text { stage II III } \\
\text { resectable rectal } \\
\text { cancer }\end{array}$} & $\begin{array}{l}\text { preoperative concurrent } \\
\text { chemoradiotherapy }(n=505)\end{array}$ & $\begin{array}{l}7.6 \\
(p=0.002)\end{array}$ & $\begin{array}{l}58.2 \\
(p=12)\end{array}$ & $\begin{array}{l}65.8 \\
(p=0.84)\end{array}$ & $\begin{array}{l}14 \\
(p \\
=0.005)\end{array}$ \\
\hline & & Preoperative radiotherapy alone $(n=506)$ & 17.1 & 52.2 & 64.8 & 5.3 \\
\hline
\end{tabular}


It is a current consensus that [11] patients with T3N0 and T1 3N1 2 rectal cancer judged by imaging should receive preoperative chemoradiotherapy. Only for those patients with contraindications, surgical resection is firstly considered. Neoadjuvant chemoradiotherapy of rectal cancer includes long-term preoperative radiotherapy, long-term preoperative concurrent chemoradiotherapy (concurrent radiotherapy, CRT) and short-term preoperative radiotherapy [12-15] (Table 2).

There are minor differences between National Comprehensive Cancer Network (NCCN) guideline and European Society for Medical Oncology (ESMO) guidelines regarding the neoadjuvant chemoradiotherapy for locally advanced rectal cancer.

NCCN guidelines suggests that, neoadjuvant and adjuvant therapy are recommended for those patients with high risk of local recurrence, including stage II (T3-4, lymph node negative, tumor invaded through the intestinal muscle layer) and stage III (positive lymph node, no distant metastasis). The recommended radiation dose is 45 50Gy in 25 28 fractions using multiple radiation fields (generally $3 \sim 4$ fields technique). Positioning and other techniques to minimize the volume of small bowel in the fields are encouraged. The treatment period for neoadjuvant chemoradiotherapy is about 5.5 6 weeks followed with 5 10 weeks interval, after which surgery is given.

European Society for Medical Oncology (ESMO) guidelines recommended for the first time in 2013, that the treatment for rectal cancer should be stratified based on the recurrence risk. The recurrence risk is mainly evaluated by the pretreatment MRI including the tumor invasion depth ( $\mathrm{T}$ staging), number of metastatic lymph nodes ( $\mathrm{N}$ staging [16], the distance to anus, invasion situation of mesorectal fascia (MRF) and extramural vascular (EMVI), etc. Patients should be divided into ultra-low-risk group, low-risk group, medium-risk group and high-risk group according to the recurrence risk. The manner of treatment after the stratification differs a lot from the traditional single treatment.

For ultra-low-risk group, surgery can be directly conducted without neoadjuvant chemoradiotherapy regardless of the tumor location. For patients with low-risk rectal cancer, which include $\mathrm{T} 1 \sim 2$, early T3N0, tumor invasion depth less than $5 \mathrm{~mm}$ assessed by MRI, unaffected mesorectal fascia (MRF) and extramural vascular (EMVI), if the tumor is located above the musculi levator ani and it is middle and low rectal cancer, surgery can be delivered directly. If pathology indicates the adverse prognostic factors including the metastatic lymph nodes or positive circumferential resection margin, chemoradiotherapy or chemotherapy should be added [17].

Medium-risk group include patients with T2 3, part of T4a (only part of peritoneum invaded), tumor invasion depth more than $5 \mathrm{~mm}$ assessed by MRI, un-affected mesorectal fascia (MRF), or/and metastatic lymph nodes. For medium-risk group patients, neoadjuvant chemoradiotherapy can significantly reduce the local recurrence rate. There is controversy in the selection of long course or short course of treatment, but long course chemoradiotherapy can bring higher $\mathrm{pCR}$ rate, and it is currently the first choice of most radiotherapy center.

Table 2. Randomize studies of preoperative short course radiotherapy ( $5 \mathrm{G} y \times 5 f)$ for rectal cancer.

\begin{tabular}{|c|c|c|c|c|c|c|c|}
\hline Studies & Time & Eligible criteria & short course radiotherapy & $\begin{array}{l}\text { Drug of concurrent } \\
\text { chemotherapy }\end{array}$ & $\begin{array}{l}\text { Interval } \\
\text { to } \\
\text { Surgery }\end{array}$ & Cases & pCR (\%) \\
\hline \multirow[t]{2}{*}{$\begin{array}{l}\text { TROG } 0104 \\
{[12]}\end{array}$} & \multirow[t]{2}{*}{2012} & $\begin{array}{l}\text { stage } \mathrm{II} \sim \text { III } \\
\text { resectable rectal } \\
\text { cancer }\end{array}$ & Short course, $5 \mathrm{~Gy} \times 5 \mathrm{f}$ & & & 163 & $\begin{array}{l}\text { 3-year local relapse } \\
\text { rate } 7.5 \%\end{array}$ \\
\hline & & & $\begin{array}{l}\text { Long course concurrent } \\
\text { chemoradiotherapy }\end{array}$ & & & 163 & $\begin{array}{l}\text { 3-year local relapse } \\
\text { rate } 4.4 \%(p=0.24)\end{array}$ \\
\hline \multirow[t]{2}{*}{$\begin{array}{l}\text { RAPIDO } \\
{[13]}\end{array}$} & \multirow[t]{2}{*}{2013} & \multirow{2}{*}{$\begin{array}{l}\text { stage II } \sim \text { III } \\
\text { resectable rectal } \\
\text { cancer }\end{array}$} & $\begin{array}{l}\text { short course radiotherapy, } \\
5 \mathrm{~Gy} \times 5 \mathrm{f} \text {, following chemotherapy }\end{array}$ & $\begin{array}{l}\text { Following Capecitabine } \\
\text { +Oxaliplatin } 6 \text { cycles }\end{array}$ & & Recruiting & \\
\hline & & & $\begin{array}{l}\text { long course concurrent } \\
\text { chemoradiotherapy, } 50.4 \mathrm{~Gy} / 28 \mathrm{f} \text {, }\end{array}$ & $\begin{array}{l}\text { Concurrent } \\
\text { chemotherapy } \\
\text { Capecitabine }\end{array}$ & & Recruiting & \\
\hline \multirow[t]{2}{*}{ Bujko [14] } & \multirow[t]{2}{*}{2013} & \multirow[t]{2}{*}{$\begin{array}{l}\text { stage II III } \\
\text { unresectable rectal } \\
\text { cancer }\end{array}$} & $\begin{array}{l}\text { short course radiotherapy, } \\
5 \mathrm{~Gy} \times 5 \mathrm{f} \text {, following chemotherapy }\end{array}$ & $\begin{array}{l}\text { Following } \\
\text { 5-FU+Oxaliplatin } 3 \\
\text { cycles }\end{array}$ & 49 & & 21 \\
\hline & & & $\begin{array}{l}\text { long course concurrent } \\
\text { chemoradiotherapy, } 50.4 \mathrm{~Gy} / 28 \mathrm{f} \text {, }\end{array}$ & 5-FU+Oxaliplatin & 48 & & 9 \\
\hline \multirow[t]{3}{*}{$\begin{array}{l}\text { Stockholm } \\
\text { III [15] }\end{array}$} & \multirow[t]{3}{*}{2010} & \multirow{3}{*}{$\begin{array}{l}\text { stage II } \sim \text { III } \\
\text { resectable rectal } \\
\text { cancer }\end{array}$} & $\begin{array}{l}\text { short course radiotherapy, } \\
5 \mathrm{G} \times 5 \mathrm{f}\end{array}$ & & 120 & $4 \sim 8$ weeks & 12.5 \\
\hline & & & $\begin{array}{l}\text { short course radiotherapy, } \\
5 \mathrm{~Gy} \times 5 \mathrm{f} \text {, }\end{array}$ & & 118 & $2 \sim 3$ days & 0.8 \\
\hline & & & $\begin{array}{l}\text { long course radiotherapy alone, } \\
50 \mathrm{~Gy} / 25 \mathrm{f} \text {, }\end{array}$ & & 65 & $4 \sim 8$ weeks & 5 \\
\hline
\end{tabular}


High-risk group include patients with T3 T4b with mesorectal fascia (MRF) invasion, or/and metastatic iliac lymph nodes. Long course chemoradiotherapy followed with TME surgery after 6 to 8 weeks is the first choice and accepted treatment modalities for high-risk group patients. For elderly patients or patients who can not tolerate long-term course of chemotherapy, 5×5Gy short course of radiotherapy can be considered.

ESMO guide recommended short course radiotherapy (1 week, $25 \mathrm{~Gy} / 5 \mathrm{f}$ ) or long course radiotherapy (45-50.4 Gy/1.8-2 Gy), combined with 5-fluorouracil (5-FU).

The advantages of neoadjuvant chemoradiotherapy include: (1) Preoperative tumor is susceptible to radiotherapy and the treatment effect is better than that of postoperative radiotherapy, as local blood supply is not damaged and tumor oxygenation is important for radiation sensitivity; (2) Preoperative neoadjuvant chemoradiotherapy can downstage tumors, which is illustrated through the decreased thickness of invaded intestinal wall and decreased numbers of metastatic lymph nodes, even to pCR. Thus preoperative chemoradiotherapy can decrease positive rate of surgical margin and increase R0 resection rate and anal sphincter preservation rate for low rectal cancer; (3) After neoadjuvant chemoradiotherapy, tumor tissue appears necrosis and fibrosis with different degrees, active tumor cells are greatly reduced, the probability of tumor cells falling off, spreading and planting during the operation are greatly reduced, thus the local reoccurrence reduces; (4) As the structure of abdomen organs are with no damage and adhesion before the neoadjuvant radiotherapy, the radiation reaction and acute toxicity reaction are minimum. Majority of patients can complete the therapeutic doses of radiotherapy with well tolerance; (5) Neoadjuvant radiotherapy can improve the local control rate.

The disadvantages of preoperative chemoradiotherapy include: (1) Patients can not obtain accurate preoperative pathologic staging in two cases including early rectal cancer (T1-T2N0) and over estimation of staging by preoperative clinical imaging [18], which will lead to certain blindness in selecting the treatment model. The other case is, if there is undiscovered distant metastasis before the surgery, the main factor affecting the prognosis is distant metastasis lesion rather than local recurrence. Thus, it is important to accurately select the patients for preoperative radiochemotherapy through improving the accuracy of preoperative imaging (including transrectal ultrasound, CT or MRI); (2) For those tumors which are insensitive to radiotherapy and chemotherapy, neoadjuvant chemoradiotherapy may delay the opportunity of surgical resection, which leads to tumor development during this period; (3) Preoperative radiotherapy increases the difficulties of surgery, especially for short-term hypofractionated radiotherapy. In the time of surgery, tumors and surrounding tissue are still in inflammatory represented as congestion and edema which can increase intraoperative bleeding. After long-term preoperative radiotherapy, tissue becomes fibrotic and tumor closely adhere to surrounding structures, which accordingly increases the difficulties of surgical separation and postoperative complications including anastomotic leakage (LAR surgery) and perineal wound dehiscence (APR surgery).

Preoperative radiotherapy is effective in downstage, increasing resection rate and local control rate, especially for patients with low rectal cancer, and increase overall survival rate for a certain part of patients. Postoperative radiotherapy is helpful to improve the local control rate.

Multivariate analysis showed the distance from tumor to anal verge, $\mathrm{T}$ stage and the response of tumor to preoperative chemoradiotherapy are independent factors affecting the sphincter preserving rate [19]. Infiltration beyond serosa, lymph node metastasis and positive circumferential margin are significant predictors for local recurrence, distant metastasis and overall survival rate [20,21].

For T3 patients with infiltration beyond serosa more than $5 \mathrm{~mm}$ who receive only surgery, their recurrence rate and prognosis are significantly worse. Thus for those T3 patients with tumor located in the middle of rectum, infiltration depth beyond serosa less than $5 \mathrm{~mm}$ and with negative lymph node, short-term preoperative radiotherapy or TME surgery alone may be enough; But for those T3 patients with infiltration beyond serosa more than $5 \mathrm{~mm}$, or with positive lymph node, or circumferential resection margin (CRM) $>1 \mathrm{~mm}$, or need Mile's surgery, long-term preoperative radiochemotherapy plus TME surgery followed by postoperative intensified chemotherapy are necessary and important. If CRM < $1 \mathrm{~mm}$, the radiation dose need to be increased and more effective combined chemotherapy need to be explored besides every other treatment are same as above [22].

\section{Preoperative radiotherapy}

\subsection{Patients selection for neoadjuvant radiotherapy}

Overtreatment in preoperative radiotherapy needs to be noted and prevented. The choice and strategy of neoadjuvant therapy is based on the 
clinical diagnosis. Because the clinical diagnosis induces $10 \%$ to $20 \%$ possibility of overestimate or underestimate, so how to select appropriate patients for neoadjuvant therapy is a study hotspot. Due to the error of preoperative staging, a small portion of T1-T2, N0 patients can be misdiagnosed into middle-risk and high-risk group, resulting in unnecessary treatment. Preoperative evaluation system needs to contain at least MRI or endo-luminal ultrasound. Even though, comparative study of preoperative therapy vs postoperative therapy published in New England Journal of Medicine in 2004 by Germany Rectal Cancer Research Group showed that there were still $18 \%$ of T1-T2N0 stage patients who have been misdiagnosed as high-risk patients (T3 or N1) by endosonography [5]. In addition, a small part of poorly differentiated rectal cancer may resist neoadjunvant treatment and tumor continues developing in the process of neoadjunvant treatment, these patients should be examined and evaluated in time. Neoadjunvant treatment can be replaced by surgery when necessary [23].

\subsection{Dispute of the indication of preoperative chemoradiotherapy}

\subsubsection{The majority of patients with T1 2N0M0 rectal cancer can be cured by surgery.}

The treatment dispute mainly exists in the mid-risk group. The data of disease-free survival rate and local failure rate showed that the survival rate of mid-risk patients has the potential to be further improved. Because preoperative radiotherapy or concurrent chemoradiotherapy can reduce the local failure of patients in stage II and III, the mid-risk group needs neoadjuvant chemoradiotherapy. There exist controversies toward selecting short-term or long-term conventional fractionated chemoradiotherapy. It showed that patients with mid-low rectal cancer and high-risk benefit from the conventional fractionated long term chemoradiotherapy [24]. Current researches have confirmed that both preoperative short-term and long-term chemoradiotherapy can contribute to the local control of T3 rectal cancer. If T3 patients can be downstaged (pT0-2) followed by neoadjuvant radiotherapy, then the adjuvant chemotherapy will contribute more.

\subsubsection{The main dispute of the indication of preoperative chemoradiotherapy is T3N0 patients.}

Researchers have studied the relations between local recurrence and different clinical features of T3 patients, including the tumor location, with or without neural invasion, and the distance from tumor to anus.
Peng et al. studied the T3N0 patients without nerve invasion and found that the 5-year local recurrence rate of these patients is only $7.9 \%$ comparing with $22.7 \% \quad(p=0.017)$ of patients with neural invasion. This suggests that for this part of T3N0 patients, the role of neoadjuvant chemoradiotherapy may be limited.

\subsubsection{Tumor invasion depth in the intestinal wall in} $\mathrm{T} 3 \mathrm{~N} 0$ patients related to the prognosis and treatment choice.

Shin analyzed 291 cases patients with T3 rectal cancer and divided patients into 4 subgroups according to the depth of invasion, T3a, < 1mm; T3b, $1.5 \mathrm{~mm}$; T3c, 5 15 mm; T3d > 15mm. Five-year Disease free of survival rates of these four subgroups were for $86.5 \%, 74.2 \%, 58.3 \%$ and $29 \%$ respectively $(\mathrm{p}<0.001)$.

Merkel et al. study showed that regardless of metastasis status of lymph node, 5-year cancer specific survival rate of patients with $\mathrm{T} 3$ tumor and the infiltration depth $<5 \mathrm{~mm}$ was $85 \%$, whereas that of T3 patients with tumor infiltration depth $\geq 5 \mathrm{~mm}$ was $54 \%$. In Mercury's study, the recurrence rate of patients who were $\mathrm{T} 3$ tumor infiltration depth $<5 \mathrm{~mm}$ and without mesorectal clearance invasion, without vascular tumor thrombus, and without high risk factors evaluated by MRI, was only $1.7 \%$ when they only received surgery. So for this part of T3N0 patients, the role of neoadjuvant chemoradiotherapy may be limited.

Classification of T3 subgroup has currently been carried out in the preoperative evaluation of rectal cancer by MRI, but has not yet been formally incorporated into the TNM staging criteria. The two classification systems for assessing the depth of invasion by MRI are ESMO and RSNA standards.

ESMO standard is described as T3a, $<1 \mathrm{~mm} ; \mathrm{T} 3 \mathrm{~b}$, $15 \mathrm{~mm}$; T3c, 5 15mm; T3d $>15 \mathrm{~mm}$. RSNA standard is described as T3a, <5mm; T3b, 5-10mm; T3c, $>15 \mathrm{~mm}$. ESMO standard is more accurate, but increased the difficulties of measuring, and with low repeatability. RSNA standard has more clinical application value.

The possibility of local recurrence varies with the tumors locations in rectum. The risk of recurrence is significantly reduced when the tumor is located more than $10 \mathrm{~cm}$ far from the anal margin, even if the patients received only surgery. Thus, neoadjuvant treatment has limited role for this part of patients. But this needs to be confirmed by large-scale randomized clinical studies.

\subsection{Radiotherapy with sphincter preservation}

A study showed when 35 patients received pelvic irradiation 55 Gy in $4 \sim 6$ weeks, there were $45 \%$ and $23 \%$ of patients respectively had the urgency of 
defecation and fecal incontinence. And internal anal sphincter or external anus sphincter were all damaged proved through resting (no-load) anal pressure and full load (squeeze) anal pressure compared with baseline [25]. The damage mechanism was not fully understood and electromyography of anal sphincter did not show abnormal nerve conduction signal, so it probably related to damage of muscle itself. Therefore, appropriate radiotherapy manner and dosage should be carefully considered [26].

Both three-dimensional conformal radiotherapy and intensity-modulated radiotherapy can reduce the actual received dose of anal sphincter without affecting the radiotherapy effect. The key point is to clearly contour the anal sphincter continuously in each slides of CT images (MRI is preferable), and restrict the dose of anal sphincter through lead blocking technology. It can reduce the received dose from original $33 \mathrm{~Gy}$ to $6 \mathrm{~Gy}$ [27]. For a certain portion of irradiation fields which include the anal sphincter and distal rectum, the dose should also be limited to 40 45 Gy [28].

\subsection{The benefits and impact of IMRT in the neoadjuvant radiotherapy for local advanced rectal cancer}

For neoadjuvant radiotherapy, Intensity modulated radiotherapy (IMRT) was used to reduce the radiation-associated toxicities by decreasing the volume of high irradiation dose of surrounding normal tissues, especially the small bowel, compared with conventional radiotherapy or three dimensional conformal radiotherapy (3DCRT) [29-31].

IMRT allows higher radiation doses to be focused on tumor while minimizing the dose to surrounding normal critical structures. Compared to conventional $2 \mathrm{D}$ or $3 \mathrm{D}$ radiation therapy, IMRT showed similar target coverage with reduced dose to the small bowel, bladder, pelvic bone and femoral heads Hartley's meta-analysis reviewed a total of 3157 rectal cancer patients and found that IMRT may provide a potential to increase treatment dose aiming to improving tumor response and decrease the dose delivered to normal structures [ 16, 21, 23, 29, 32-39].

Studies also compared volumetric modulated arc therapy (VMAT) and IMRT in patients with locally advanced rectal cancer (LARC) when treated with neoadjuvant chemoradiotherapy. Wen's study found that VMRT showed similar target coverage as IMRT does but with superior normal tissue sparing [40]. This indicates VMAT may be better in neoadjuvant radiotherapy, but this need more studies and evidence.

\section{Selection of concurrent preoperative chemoradiotherapy scheme}

\section{Capecitabine vs 5-FU}

Multiple phase I studies of concurrent chemoradiotherapy have proved the safety of capecitabine in $1600 \mathrm{mg} /\left(\mathrm{m}^{2} \cdot \mathrm{d}\right)$ and $1650 \mathrm{mg} /\left(\mathrm{m}^{2} \cdot \mathrm{d}\right)$ combined with preoperative radiotherapy $[12,36,37$, 41-43]. Phase II studies have indicated that the downstage rate and pathologic complete response rate $(9.2 \% \sim 31 \%)$ of preoperative capecitabine are similar with that of preoperative 5-FU [35, 39, 44-48]. In 2009, NCCN also recommended capecitabine as a radiotherapy sensitizer for the concurrent preoperative chemoradiotherapy of rectal cancer [49].

In 2011 ASCO, NASBP R-04 firstly randomly compared the effect of capecitabine and 5-FU in preoperative concurrent chemoradiotherapy of rectal cancer. Their results proved that there was no significant difference in $\mathrm{pCR}$ rate and third-degree and fourth-degree of adverse reactions rate between capecitabine and 5-FU, which confirmed capecitabine was suitable for preoperative chemoradiotherapy for rectal cancer [50].

A phase III clinical multicenter, randomized, non-inferiority study published recently also confirmed the position of capecitabine in adjuvant and neoadjuvant radiotherapy/chemotherapy of locally advanced rectal cancer. Their results showed that there was no statistical difference of 3 years' DFS and local recurrence rate between capecitabine and 5-FU. It suggested capecitabine can replace 5-FU as adjuvant or neoadjuvant chemotherapy for locally advanced rectal cancer [38].

\section{Oxaliplatin}

In the concurrent preoperative chemoradiotherapy of locally advanced rectal cancer, will the effect of combination of oxaliplatin with capecitabine or 5-FU be better than that of single drug of capecitabine or 5-FU [51]? There are 4 prospective phase III randomized studies focus on this issue including STAR-01, ACCORD12/0405, NSABPR-04 and PETACC $6[50,52-55]$ (Table 3).

Studies showed that combination oxaliplatin with capecitabine or 5-FU failed to increase the pCR rate or downstage rate comparing to single drug, while dramatically increased the third-degree and fourth-degree of adverse effects. ACCORD 12/0405 reported that there was no significant difference in 3 -year local recurrence rate ( $4 \%$ vs. $6 \%$ ), disease-free survival rate $(74 \%$ vs $69 \%)$ and overall survival rate (both $88 \%$ ) between combined two drugs and single drug. Therefore, NCCN recommends the standard drug of preoperative concurrent chemoradiotherapy 
for rectal cancer is still single capecitabine or 5-FU [50, 53-55] (Table 3).

\section{Evaluation criteria for the efficacy of neoadjuvant therapy for rectal cancer}

How to evaluate the efficacy of preoperative concurrent chemoradiotherapy for local advanced rectal cancer? The criteria are very important. Evaluation methods include clinical symptoms, serum biomarkers and imagings including transrectal ultrasound (ERUs), computer tomography (CT), magnetic resonance imaging (MRI), and positron emission tomography (PET) [56, 57]. Furthermore, the following two issues are worth of attention $[58,9]$.

\section{Molecular markers}

The relativity between microsatellite instability (MSI) and prognosis and efficacy of chemotherapy for rectal cancer is a hotspot of molecular marker research at present $[60,61]$. Ribic's study showed that MSI may indicate the good prognosis of rectal cancer patients [62]. Sargent reported the lack of mismatch repair protein (dMMR) was associated with MSI, and dMMR might be an independent predictor of good prognosis [63].

\section{Evaluation criterion of efficacy of neoadjuvant therapy for rectal cancer}

RECIST criterion (2000, version 1.0, 2009, version

1.1): considering the defects of WHO criterion, European Association of Cancer Research and Treatment, the U.S. National Cancer Institute and Canadian National Cancer Institute published a new

Table 3. Randomize studies of preoperative concurrent chemoradiotherapy with Oxaliplatin for rectal cancer.

\begin{tabular}{|c|c|c|c|c|c|}
\hline Studies & Time & $\begin{array}{l}\text { Concurrent } \\
\text { chemotherapy } \\
\text { Groups }\end{array}$ & $\begin{array}{l}\text { Dose of } \\
\text { concurrent } \\
\text { radiotherapy }\end{array}$ & Cases & pCR (\%) \\
\hline \multirow[t]{2}{*}{ ACCORD [54] } & \multirow[t]{2}{*}{2010} & Capecitabine & $45 \mathrm{~Gy} / 25 \mathrm{f}$ & 299 & $\begin{array}{l}13.9 \\
(p=0.09)\end{array}$ \\
\hline & & $\begin{array}{l}\text { Capecitabine } \\
\text { combined with } \\
\text { oxaliplatin }\end{array}$ & $50 \mathrm{~Gy} / 25 \mathrm{f}$ & 299 & 19.2 \\
\hline \multirow[t]{2}{*}{ STAR-01 [53] } & \multirow[t]{2}{*}{2011} & $5-\mathrm{FU}$ & \multirow[b]{2}{*}{$50.4 \mathrm{~Gy} / 28 \mathrm{f}$} & 379 & $\begin{array}{l}16 \\
(p=0.904)\end{array}$ \\
\hline & & $\begin{array}{l}\text { 5-FU combined } \\
\text { with oxaliplatin }\end{array}$ & & 368 & 16 \\
\hline \multirow[t]{2}{*}{$\begin{array}{l}\text { NSABP R04 } \\
{[50]}\end{array}$} & \multirow[t]{2}{*}{2011} & $\begin{array}{l}\text { 5-FU / } \\
\text { Capecitabine }\end{array}$ & \multirow[t]{2}{*}{$\begin{array}{l}50.4 \sim 55.8 \\
\text { Gy/25f }\end{array}$} & \multirow[t]{2}{*}{1608} & $\begin{array}{l}19.1 \\
(p=0.46)\end{array}$ \\
\hline & & $\begin{array}{l}\text { 5-FU / } \\
\text { Capecitabine } \\
\text { combined with } \\
\text { oxaliplatin }\end{array}$ & & & 20.9 \\
\hline \multirow[t]{2}{*}{$\begin{array}{l}\text { CAO/AR0-04 } \\
\text { [55] }\end{array}$} & \multirow[t]{2}{*}{2012} & 5-FU(W1,2,4,5) & \multirow[t]{2}{*}{$50.4 \mathrm{~Gy} / 28 \mathrm{f}$} & 624 & $\begin{array}{l}12.3 \\
(p=0.045)\end{array}$ \\
\hline & & $\begin{array}{l}\text { 5-FU combined } \\
\text { with oxaliplatin } \\
(\mathrm{W} 1,2,4,5)\end{array}$ & & 613 & 16.5 \\
\hline
\end{tabular}

evaluation RECIST criterion in solid tumors in 2000 $[64,65]$. New criteria clearly define the size of minimum tumor focus, total numbers of target lesions and viscera restrictions in details, and avoid over evaluation of progression as WHO criterion does. RECIST criterion clearly classifies tumors into measurable lesions and immeasurable lesions.

Measurable lesions refers to tumor lesions with diameter $\geq 20 \mathrm{~mm}$ by routine examination method or diameter $\geq 10 \mathrm{~mm}$ by spiral CT. Immeasurable lesions are all other lesions except measurable lesions, including lesions with diameter less than specified size, bone lesions, meningeal lesions, peritoneal effusion, pleural effusion, pericardial effusion, abdominal mass and cystic lesions which can not be confirmed and evaluated by imaging. However, RECIST criteria still have its limitations including the followings: single diameter measurement is not suitable for tumor with non-peripheral growing manner; changes in tumor size can not fully reflect the tumor biological characteristics after treatment; anatomical changes come more slowly than functional changes; the evaluation for tumor in cavity organ is not accurate enough [56].

\section{Effect of preoperative chemoradiotherapy affecting the choice of surgery}

Habr-Gama et al. found that 5-year overall survival (OS) rateand disease free survival (DFS) rate of those patients who obtained clinical complete remission (CCR) through preoperative chemoradiotherapy can reached $83 \%$ and $92 \%$ respectively, and the local recurrence rate of patients who undergo waiting for observation after CCR was 31\% [66]. Therefore caution needs to be taken in waiting and observing strategy and non-operative treatment on the patients with CCR after preoperative chemoradiotherapy. In Belluco's retrospective analysis of 139 cases of T3N0 1 patients with rectal cancer, there were no statistical significant difference of overall survival rate between patients received TME resection and patients received partial resection who all obtained pCR after neoadjuvant chemoradiotherapy [67]. The evidence suggested that the intensity of the following treatment can be reduced if patients with CCR have achieved neoadjuvant chemoradiotherapy. Suitable population must be paid attention. It also needs to judge and consider the balance between the higher recurrence rate and the higher sphincter preserving rate. In addition, 
the evaluation of the efficacy of neoadjuvant radiochemotherapy should be as enough as possible. It needs to maximally improve the accuracy of evaluation [24].

\section{Interval time between neoadjuvant therapy and surgery}

Up to now, it is hard to recommend specific interval time between the neoadjuvant therapy and followed surgery. There are two famous researches which studied the suitable interval time between the neoadjuvant therapy and followed surgery. First study is Lyon trial which was from 1990 to 2001 [68]. The neoadjuvant radiotherapy dose is 39 Gy/13 times. Group 1 took the short interval time and Group 2 took longer interval time, 6-8 weeks. The effective rate of radiotherapy of group 1 and group 2 were $53.1 \%$ and $71.7 \%$ respectively. The pathologic downstage rate of group 1 and group 2 were 10.3\% and $26 \%$ respectively. The anus preservation rate of group 1 and group 2 were was $68 \%$ and $76 \%$ respectively. This result suggested that long interval time is better than short interval time.

The second research is a prospective analysis of 397 patients with locally advanced rectal cancer who underwent surgical resection $4 \sim 8$ weeks (interval time) after the neoadjuvant chemoradiotherapy. They studied the difference between group A $(4 \mathrm{~W} \sim 6 \mathrm{~W}$ interval time) and group B ( $6 \mathrm{~W} \sim 8 \mathrm{~W}$ interval time) [69]. They found that the efficiency of chemoradiotherapy of group B can not be further improved, and the rate of complications and local recurrence rate of group B can not be further reduced compared with group A.

So, the interval time of $4 \sim 6$ weeks after the neoadjuvant chemoradiotherapy before surgery is recommended.

\section{Use of metformin during neoadjuvant therapy}

Studies suggest that metformin may be an effective chemopreventive agent in neoadjuvant chemoradiotherapy of locally advanced rectal cancer [70]. Some study examined the effect of metformin use on pathologic complete response $(\mathrm{pCR})$ rates and outcomes in rectal cancer. Metformin users have significantly higher $\mathrm{pCR}$ rates than either nondiabetics or diabetics not using metformin. Metformin use was significantly associated with pCR rate on univariate and multivariate analyses.

Furthermore, patients taking metformin had significantly increased disease-free and overall survival compared with other diabetic patients. Metformin use is associated with significantly higher
pCR rates as well as improved survival. Thus, metformin may be helpful in the neoadjuvant chemoradiotherapy of locally advanced rectal cancer.

\section{Preoperative chemotherapy}

There is new direction of preoperative chemotherapy study, introducing sequential concurrent chemoradiotherapy before the surgery.

\section{Sequential concurrent neoadjuvant chemoradiotherapy}

There have been some phase II clinical studies in this area, and got some encouraging results, pCR of $14 \%-36 \%$ observed. A Spanish study compared group 1 (4 cycles of XELOX, followed by concurrent neoadjuvant chemoradiotherapy with XELOX, followed by surgery) and group 2 (concurrent neoadjuvant chemoradiotherapy with XELOX, followed by surgery, followed by 4 cycles of XELOX adjuvant chemotherapy). The conclusion is inducing chemotherapy and sequential concurrent neoadjuvant chemoradiotherapy can be implemented; Preoperative chemotherapy was better tolerated than postoperative chemotherapy; Inducing chemotherapy did not increase the toxicity of concurrent chemoradiotherapy; The $\mathrm{R} 0$ resection rate and $\mathrm{pCR}$ rate of inducing chemotherapy followed by concurrent chemoradiotherapy were same as those of preoperative chemotherapy alone. These phase II studies give us a lot of inspiration. At present, phase III study, RAPIDO research, has been carried out in Europe. NCCN guidelines have recommended inducing chemotherapy combined with sequential synchronous chemoradiotherapy as a $2 \mathrm{~A}$ grade suggestion.

\section{Some questions of neoadjuvant chemoradiation for locally advanced rectal cancer need further study}

Although some clinical trials have currently revealed the standard of neoadjuvant chemoradiotherapy for locally advanced rectal cancer, there are still some questions need further study[71]: (1) Whether treatment effect can be improved by increasing the radiation dose or not? (2) In the study of ASAR-01, the combination of drugs, oxaliplatin, reduced the intraperitoneal metastasis during the operation, whether it can also increase overall survival rate or not? (3) How to accurately recognize the insensitive patients in order to avoid over-treatment on insensitive patients? (4) The necessity of stratified treatment? Is it good to apply single chemotherapy drug for low-risk patients and combined chemotherapy drug for high-risk-patients? 
Hope there would be more clinical trials to answer these questions.

In summary, neoadjuvant chemoradiotherapy is still the standard treatment mode for locally advanced rectal cancer. Taking a more personalized treatment scheme is a trend for patients with mid-risk rectal cancer; for mid-risk and high-risk patients, more effective combined therapeutic means is the future direction.

\section{Competing Interests}

The authors have declared that no competing interest exists.

\section{References}

1. Lemmens V, Steenbergen LV, Janssenheijnen M, Martijn $H$, Rutten $H$, Coebergh JW. Trends in colorectal cancer in the south of the Netherlands 1975-2007: Rectal cancer survival levels with colon cancer survival. Acta Oncol. 2010; 49: 784-96.

2. Glimelius B, editor Multidisciplinary treatment of patients with rectal cancer: Development during the past decades and plans for the future. Mechatronics and Automation (ICMA), 2012 International Conference on; 2012.

3. Hwang K, Park IJ, Chang SY, Lim SB, Lee JL, Yong SY, et al. Impression of prognosis regarding pathologic stage after preoperative chemoradiotherapy in rectal cancer. World J Gastroenterology. 2015: 555-62.

4. Brændengen M, Tveit KM, Berglund §, Birkemeyer E, Frykholm G, Påhlman L, et al. Randomized Phase III Study Comparing Preoperative Radiotherapy With Chemoradiotherapy in Nonresectable Rectal Cancer. J Clinical Oncology. 2008; 26: 3687-94

5. R S, H B, W H, C R, C W, R F, et al. Preoperative versus postoperative chemoradiotherapy for rectal cancer. New Engl J Med. 2004; 351: 1731-40.

6. Roh MS, Colangelo LH, O'Connell MJ, Yothers G, Deutsch M, Allegra CJ, et al. Preoperative multimodality therapy improves disease-free survival in patients with carcinoma of the rectum: NSABP R-03. J Clin Oncol. 2009; 27: 5124-30.

7. Bujko K, Nowacki MP, Nasierowska-Guttmejer A, Michalski W, benek MBjm, Pudełko $\mathrm{M}$, et al. Sphincter preservation following preoperative radiotherapy for rectal cancer: report of a randomised trial comparing short-term radiotherapy vs. conventionally fractionated radiochemotherapy. Radiotherapy \& Oncology Journal of the European Society for Therapeutic Radiology \& Oncology. 2004; 72: 15-24.

8. Gérard JP, Conroy T, Bonnetain F, Bouché O, Chapet O, Closon-Dejardin MT, et al. Preoperative radiotherapy with or without concurrent fluorouracil and leucovorin in T3-4 rectal cancers: results of FFCD 9203. J Clin Oncol 2006; 24: 4620-25.

9. Bosset JF, Collette L, Calais G, Mineur L, Maingon P, Radosevicjelic L, et al. Chemotherapy with preoperative radiotherapy in rectal cancer. New Engl J Med. 2006; 355: 1114-23.

10. Serra-Aracil X, Mora-Lopez L, Alcantara-Moral M, Caro-Tarrago A, Gomez-Diaz CI, Navarro-Soto S. Transanal endoscopic surgery in rectal cancer. World J Gastroenterol. 2014; 20: 11538-45.

11. Wang ZZ, Zhou ZX. Radiotherapy In Comprehensive Treatment Of Low Rectal Cancer Multidisciplinary Significance. Practical Oncology. 2011; 26: 13-16.

12. Ngan SY, Burmeister B, Fisher RJ, Solomon M, Goldstein D, Joseph D, et al. Randomized trial of short-course radiotherapy versus long-course chemoradiation comparing rates of local recurrence in patients with T3 rectal cancer: Trans-Tasman Radiation Oncology Group Trial 01.04. Journal of Clinical Oncology Official Journal of the American Society of Clinical Oncology. 2012; 30: 3827-33.

13. Nilsson PJ, Etten BV, Hospers GA, Påhlman L, Velde CJVD, Beets-Tan RG, et al. Short-course radiotherapy followed by neo-adjuvant chemotherapy in locally advanced rectal cancer - the RAPIDO trial. Bmc Cancer. 2013; 13: 1-9.

14. Bujko K, Nasierowska-Guttmejer A, Wyrwicz L, Malinowska M, Krynski J, Kosakowska E, et al. Neoadjuvant treatment for unresectable rectal cancer: An interim analysis of a multicentre randomized study. Radiotherapy \& Oncology. 2013; 107: 171-77.

15. Pettersson D, Cedermark B, Holm T, Radu C, Påhlman L, Glimelius B, et al. Interim analysis of the Stockholm III trial of preoperative radiotherapy regimens for rectal cancer t. Bri J Surgery. 2010; 97: 580-87.

16. Park, Chang, Seok-Byung, Yong, Yoon, Chan, et al. Ratio of metastatic lymph nodes is more important for rectal cancer patients treated with preoperative chemoradiotherapy. World J Gastroenterol. 2015; 21: 3274-81.

17. Aoife, Maguire, Kieran, Sheahan. Controversies in the pathological assessment of colorectal cancer. World J Gastroenterol. 2014; 20: 9850-61.

18. Daniel, Damin, Anderson, Lazzaron. Evolving treatment strategies for colorectal cancer: A critical review of current therapeutic options. World J Gastroenterol. 2014; 20: 877-87.
19. Park, Chang. Current issues in locally advanced colorectal cancer treated by preoperative chemoradiotherapy. World J Gastroenterol. 2014; 20: 2023-29.

20. Birbeck KF, Macklin CP, Tiffin NJ, Parsons W, Dixon MF, Mapstone NP, et al. Rates of circumferential resection margin involvement vary between surgeons and predict outcomes in rectal cancer surgery. Ann Surg. 2002; 235: 449-57.

21. Rödel C, Grabenbauer GG, Papadopoulos T, Bigalke M, Günther K, Schick C, et al. Apoptosis as a cellular predictor for histopathologic response to neoadjuvant radiochemotherapy in patients with rectal cancer. International Journal of Radiation Oncologybiologyphysics. 2002; 52: 294-303.

22. Wang FW, Wang HT, Yin XD, Zhang L, Zhang T, Zhang MZ. The value of neoadjuvantchemotherapy in rectal cancer in the Chinese. J Integr Med. 2011; 17: $22-24$.

23. Costi R, Leonardi F, Zanoni D, Violi V, Roncoroni L. palliative care and end-stage colorectal cancer management:The surgeon meets the oncologist. World J of Gastroenterol. 2014; 20: 7602-21.

24. Zhang Z. Radiation therapy for middle and low rectum cancer. Chinese Jounal of Surgery 2014; 34: 854-856.

25. Yeoh EK, Russo A, Botten R, Fraser R, Roos D, Penniment M, et al. Acute effects of therapeutic irradiation for prostatic carcinoma on anorectal function. Gut. 1998; 43: 123-7.

26. Jin YN. A Hot Issue Of Low Rectal Cancer Radiotherapy. Surgical Theory And Practice. 2010; 15: 111-114.

27. Gervaz PA, Wexner SD, Pemberton JH. Pelvic radiation and anorectal function: introducing the concept of sphincter-preserving radiation therapy 1 . J Am Coll Surgeons. 2002; 195: 387-94.

28. Gervaz P, Lavertu S, Kazemba B, Pemberton JH, Haddock MG, Gunderson LL. Sphincter-preserving radiation therapy for rectal cancer: a simulation study using three-dimensional computerized technology. Colorectal Dis. 2006; 8: 570-4.

29. Urbano MTG, Henrys AJ, Adams EJ, Norman AR, Bedford JL, Harrington KJ, et al. Intensity-modulated radiotherapy in patients with locally advanced rectal cancer reduces volume of bowel treated to high dose levels. Int J Radiat Oncol Biol Phys. 2006; 65: 907-16.

30. Arbea L, Ramos LI, Martínez-Monge R, Moreno M, Aristu J. Intensity-modulated radiation therapy (IMRT) vs. 3D conformal radiotherapy (3DCRT) in locally advanced rectal cancer (LARC): dosimetric comparison and clinical implications. Radiat Oncol. 2010; 5: 1-9.

31. Caravatta L, Padula GDA, Picardi V, Macchia G, Deodato F, Massaccesi M, et al. Concomitant boost radiotherapy and multidrug chemotherapy in the neoadjuvant treatment of locally advanced rectal cancer: Results of a phase II study. Acta Oncologica. 2011; 50: 1151-57.

32. Mok $\mathrm{H}$, Crane $\mathrm{CH}$, Palmer MB, Briere TM, Beddar $\mathrm{S}$, Delclos $\mathrm{ME}$, et al. Intensity modulated radiation therapy (IMRT): differences in target volumes and improvement in clinically relevant doses to small bowel in rectal carcinoma. Radiat Oncol. 2011; 6: 1-9.

33. Wolff HA, Wagner DM, Conradi LC. Irradiation with protons for the individualized treatment of patients with locally advanced rectal cancer: a planning study with clinical implications. Indengchemfundamen. 2012; 102: 30-7.

34. Hartley A, Ho KF, Mcconkey C, Geh JI. Pathological complete response following pre-operative chemoradiotherapy in rectal cancer: analysis of phase II/III trials. Br J Radiol. 2005; 78: 934-8.

35. Kocakova I, Svoboda M, Kubosova K, Chrenko V, Roubalova E, Krejci E, et al. Preoperative radiotherapy and concomitant capecitabine treatment induce thymidylate synthase and thymidine phosphorylase mRNAs in rectal carcinoma. Neoplasma. 2007; 54: 447-53.

36. Xiao $\mathrm{Q}$, Jin J. The principle of neoadjuvant and adjuvant radiotherapy for lower rectal carcinoma:discussion with surgeons. Chinese Journal of Practical Surgery. 2012; 32: 724-727.

37. Veerasarn V, Phromratanapongse P, Lorvidhaya V, Lertsanguansinchai P, Lertbutsayanukul C, Panichevaluk A, et al. Preoperative capecitabine with pelvic radiotherapy for locally advanced rectal cancer (phase I trial). Journal of the Medical Association of Thailand = Chotmaihet thangphaet. 2006; 89: 1874-84.

38. Hofheinz RD, Wenz F, Post S, Matzdorff A, Laechelt S, Hartmann JT, et al. Chemoradiotherapy with capecitabine versus fluorouracil for locally advanced rectal cancer: a randomised, multicentre, non-inferiority, phase 3 trial. Lancet Oncology. 2012; 13: 579-88.

39. De PA, Chiara SG, Friso ML, Beretta GD, Del PS, Pasetto L, et al Capecitabine in combination with preoperative radiation therapy in locally advanced, resectable, rectal cancer: a multicentric phase II study. Ann Oncol. 2006; 17: 246-51.

40. Wen G, Zhang J, Chi F, Chen L, Huang S, Niu S, et al. Dosimetric Comparison of Volumetric Modulated Arc Therapy (VMAT), 5F Intensity Modulated Radiotherapy (IMRT) and 3D Conformal Radiotherapy (3DCRT) in Rectal Carcinoma Receiving Neoadjuvant Chemoradiotherapy. International Journal of Medical Physics Clinical Engineering \& Radiation Oncology. 2015; 04: 54-63.

41. Dunst J, Reese T, Sutter T, Zühlke H, Hinke A, Köllingschlebusch K, et al. Phase I trial evaluating the concurrent combination of radiotherapy and capecitabine in rectal cancer. Journal of Clinical Oncology Official Journal of the American Society of Clinical Oncology. 2002; 20: 3983-91.

42. Souglakos J, Androulakis N, Mavroudis D, Kourousis C, Kakolyris S, Vardakis $\mathrm{N}$, et al. Multicenter dose-finding study of concurrent capecitabine and radiotherapy as adjuvant treatment for operable rectal cancer. Int J Radiat Oncol Biol Phys. 2003; 56: 1284-7. 
43. Jin J, Li YX, Liu YP, Wang WH, Song YW, Li T, et al. A Phase I study of concurrent radiotherapy and capecitabine as adjuvant treatment for operable rectal cancer. Int J Radiat Oncol Biol Phys. 2006; 64: 725-9.

44. Kim JS, Kim JS, Cho MJ, Song KS, Yoon WH. Preoperative chemoradiation using oral capecitabine in locally advanced rectal cancer. Int J Radiat Oncol. 2002; 54: 403-8.

45. JC K, TW K, JH K, CS Y, HC K, HM C, et al. Preoperative concurrent radiotherapy with capecitabine before total mesorectal excision in locally advanced rectal cancer. Int J Radiat Oncol. 2005; 63: 346-53.

46. Dupuis O, Vie B, Lledo G, Hennequin C, Noirclerc M, Bennamoun M, et al. Preoperative treatment combining capecitabine with radiation therapy in rectal cancer: a GERCOR Phase II Study. Oncology. 2007; 73: 169-76.

47. Martin M, Cerezo L, Couñago F, Martin-Angulo M, Lopez M, Marin A, et al. A phase II study of preoperative capecitabine and radiation therapy in patients with rectal cancer. Am J Clin Oncol. 2007; 30: 340-5.

48. Craven I, Crellin A, Cooper R, Melcher A, Byrne P, Sebag-Montefiore D. Preoperative radiotherapy combined with 5 days per week capecitabine chemotherapy in locally advanced rectal cancer. Br J Cancer. 2007; 97: 1333-7.

49. CS Y, TW K, JH K, WS C, HC K, HM C, et al. Optimal time interval between capecitabine intake and radiotherapy in preoperative chemoradiation for locally advanced rectal cancer. Int J Radiat Oncol Bio Phys. 2007; 67: 1020-6.

50. Roh MS, Yothers GA, O'Connell MJ. The impact of capecitabine and oxaliplatin in the preoperative multimodality treatment in patients with carcinoma of the rectum: NSABP R-04. Proceedings of the ASCO Annual Meeting Proceedings. 2011; 3503.

51. Eagleton N. Silencing Fas-associated phosphatase 1 expression enhances efficiency of chemotherapy for colon carcinoma with oxaliplatin. World J Gastroenterol. 2010; 16: 112-8.

52. Carrato A. Adjuvant treatment of colorectal cancer. Zeitschrift Für Gastroenterologie Verhandlungsband. 1988; 23: 168-85.

53. C A, L C, Lonardi S, Pinto C, Cordio S, Rosati G, et al. Primary tumor response to preoperative chemoradiation with or without oxaliplatin in locally advanced rectal cancer: pathologic results of the STAR-01 randomized phase III trial. J Clin Oncol. 2011; 29: 2773-80.

54. Gérard JP, Azria D, Gourgou-Bourgade S, Martel-Laffay I, Hennequin C, Etienne PL, et al. Comparison of two neoadjuvant chemoradiotherapy regimens for locally advanced rectal cancer: results of the phase III trial ACCORD 12/0405-Prodige 2. J Clin Oncol. 2010; 28: 1638-44.

55. Roedel C, Grabenbauer GG, Hohenberger W, Papadopoulos T, Sauer R, Roedel C, et al. O-0028 * PREOPERATIVE CHEMORADIOTHERAPY AND POSTOPERATIVE CHEMOTHERAPY WITH 5-FLUOROURACIL AND OXALIPLATIN VERSUS 5-FLUOROURACIL ALONE IN LOCALLY ADVANCED RECTAL CANCER: RESULTS OF THE GERMAN CAO/ARO/AIO-04 RANDOMIZED PHASE III TRIAL. Ann Oncol. 2012; 13: 679-87.

56. Zhao HC, Gao C. Evaluation criteria of the efficacy of neoadjuvant therapy for colorectal cancer. J Digest Dis. 2011; 31: 253-255.

57. Boxberger F, Albrecht H, Konturek PC, Reulbach U, Maennlein G, Meyer T, et al. Neoadjuvant treatment with weekly high-dose 5-fluorouracil as a 24h-infusion, folinic acid and biweekly oxaliplatin in patients with primary resectable liver metastases of colorectal cancer: long-term results of a phase II trial. Medical Science Monitor International Medical Journal of Experimental \& Clinical Research. 2010; 16: 19-30.

58. Kekelidze M, D'Errico L, Pansini M, Tyndall A, Hohmann J. Colorectal cancer:Current imaging methods and future perspectives for the diagnosis, staging and therapeutic response evaluation. World J Gastroenterol. 2013; 19: 8502-14.

59. Hospers GA, Punt CJA, Tesselaar ME, Cats A, Havenga K, Leer JWH, et al. Preoperative chemoradiotherapy with capecitabine and oxaliplatin in locally advanced rectal cancer. A phase I-II multicenter study of the Dutch Colorectal Cancer Group. Ann Surg Oncol. 2007; 14: 455-61.

60. Des GG, Uzzan B, Nicolas P, Schischmanoff O, Perret GY, Morere JF. Microsatellite instability does not predict the efficacy of chemotherapy in metastatic colorectal cancer. A systematic review and meta-analysis. Anticancer Res. 2009; 29: 1615-20.

61. Guetz GD, Schischmanoff O, Nicolas P, Perret G-Y, Morere J-F, Uzzan B. Does microsatellite instability predict the efficacy of adjuvant chemotherapy in colorectal cancer? A systematic review with meta-analysis. Eur J Cancer. 2009; 45: 1890-6.

62. Ribic CM, Sargent DJ, Moore MJ, Thibodeau SN, French AJ, Goldberg RM, et al. Tumor microsatellite-instability status as a predictor of benefit from fluorouracil-based adjuvant chemotherapy for colon cancer. New Eng J Med. 2003; 349: 247-57.

63. Sargent DJ, Marsoni S, Monges G, Thibodeau SN, Labianca R, Hamilton SR, et al. Defective mismatch repair as a predictive marker for lack of efficacy of fluorouracil-based adjuvant therapy in colon cancer. Journal of Clinical Oncology Official Journal of the American Society of Clinical Oncology. 2010; 28: 3219-26.

64. Eisenhauer EA, Therasse P, Bogaerts J, Schwartz LH, Sargent D, Ford R, et al. New response evaluation criteria in solid tumours: Revised RECIST guideline (version 1.1). Eur J Cancer. 2009; 45: 228-47.

65. Yoshiaki Tsuchida MD, Patrick Therasse MD. Response evaluation criteria in solid tumors (RECIST): New guidelines. Medical \& Pediatric Oncology. 2001; 37: $1-3$.
66. Habr-Gama A, Gama-Rodrigues J, Julião GPS, Proscurshim I, Sabbagh C, Lynn PB, et al. Local Recurrence After Complete Clinical Response and Watch and Wait in Rectal Cancer After Neoadjuvant Chemoradiation: Impact of Salvage Therapy on Local Disease Control. Int J Radiat Oncol Bio Phys. 2014; 88: 822-8.

67. Belluco C, Paoli AD, Canzonieri V, Sigon R, Fornasarig M, Buonadonna A, et al. Long-Term Outcome of Patients with Complete Pathologic Response after Neoadjuvant Chemoradiation for cT3 Rectal Cancer: Implications for Local Excision Surgical Strategies. Ann Surg Oncol. 2011; 18: 3686-93.

68. Gerard JP, Francois Y, Nemoz C, Adeleine P. 55 Influence of the interval between pre-operative radiotherapy (preop-XRT) and surgery on the downstaging and sphincter preservation for the rectal cancer, the lyon R90 01 randomized trial. Journal of Thoracic \& Cardiovascular Surgery. 1999; 45: 2396-2396.

69. Lim S, Choi H, Sy, Kim D, Jung K, Hong Y, Chang H, et al. Optimal surgery time after preoperative chemoradiotherapy for locally advanced rectal cancers. Ann Surg. 2008; 248: 243-51.

70. Skinner HD, Crane CH, Garrett CR, Eng C, Chang GJ, Skibber JM, et al. Metformin use and improved response to therapy in rectal cancer. Cancer Medicine. 2013; 2: 99-107.

71. Trakarnsanga A, Ithimakin S, Weiser MR. Treatment of locally advanced rectal cancer: Controversies and questions. World J Gastroenterol. 2012; 18: 5521-32. 